\title{
Merkel Cell Carcinoma by AJCC v8 Pathologic Stage
}

National Cancer Institute

\section{Source}

National Cancer Institute. Merkel Cell Carcinoma by A/CC v8 Pathologic Stage. NCI

Thesaurus. Code C136880.

A term that refers to the pathologic staging of Merkel cell carcinoma (primary cutaneous neuroendocrine carcinoma), following the rules of the TNM AJCC v8 classification system. 